\title{
Social commerce from the information systems perspective: a systematic literature review
}

\begin{abstract}
The evolution of social media has changed the conventional e-commerce to social commerce. The delayed growth of the social commerce is however relatively low researched in the Information Systems disciple despite its intense evolution. As a result, this paper aims to critically probe into existing and related work in the area of social commerce from the Information Systems perspective. The standard systematic literature review method employing a physical search of 12 journals and 6 conference proceedings were used in conducting the literature review. The comprehensive systematic literature review is valuable in bridging the social commerce gap and opens up novel directions to Information Systems scholars in this market segment.
\end{abstract}

Keyword: Social commerce; Social media; Information systems; Systematic literature review 